\title{
Atividade e Vulnerabilidade: Quais os Arranjos Familiares em Risco?*
}

\author{
Lena Lavinas \\ Marcelo Nicoll
}

\begin{abstract}
$\mathrm{M}$ uito se fala na imensa vulnerabilidade dos arranjos familiares com filhos, notadamente naqueles cuja chefia é feminina e nos quais o cônjuge masculino é ausente. Sabendo-se que não há políticas permanentes e universais de apoio às famílias no Brasil, e que, portanto, grande parte do que poderia ser desmercantilizado por intermédio de políticas públicas para compensar dignamente o aporte das famílias - leia-se das mulheres - não o é, sendo assumido, na prática, na esfera privada dos lares, nem de longe se pretende contestar evidência tão cristalina. Porém, diante de tamanho vácuo no campo das políticas às famílias, será que o maior ônus recai nas famílias monoparentais femininas? Quais os arranjos familiares mais fragilizados pela ausência de um sistema de proteção social que dê segurança, reduza a vulnerabilidade e promova a eqüidade?
\end{abstract}

O mercado de trabalho e o perfil do sistema de proteção social são dois fatores explicativos do maior ou menor grau de vulnerabilidade social, estando, portanto, diretamente relacionados aos níveis de pobreza e

\footnotetext{
*Parte deste artigo foi desenvolvida no documento intitulado "Proteção Social e Justiça Redistributiva: Como Promover a Igualdade de Gênero" (Lavinas e Dain, 2005). Agradecemos ao prof. Getúlio Borges, do Instituto de Economia da Universidade Federal do Rio de Janeiro - IE/UFRJ, seus comentários críticos acerca da modelagem realizada na segunda parte deste trabalho, "Fatores que Contribuem para a Vulnerabilidade Familiar", bem como ao professor José Eustáquio Alves, da Escola Nacional de Geografia e Estatística - ENCE, por sua contribuição em uma leitura preliminar deste artigo.
}

DADOS - Revista de Ciências Sociais, Rio de Janeiro, Vol. 49, n-1, 2006, pp. 67 a 97. 
desigualdade observados em uma sociedade. Vejamos como operam no que tange às desigualdades entre os sexos.

É de conhecimento notório que, além do hiato educacional entre os sexos já ter sido revertido, no Brasil, em favor das mulheres, em todos os níveis de escolaridade, desde meados da década de 1980 (Guedes, 2004; Beltrão e Alves, 2004), a tendência à redução dos diferenciais de rendimentos entre homens e mulheres no mercado de trabalho é constante ao longo das últimas décadas (Lavinas, 2001) ${ }^{1}$.

Até 1970, a taxa de atividade feminina era inferior a 20\% (Silva e Schwarzer, 2002), quando passa a crescer então de forma mais sustentada, explicando a feminização do emprego de forma constante e linear (Lavinas, 2001). Nos últimos 20 anos, a taxa de atividade das mulheres na faixa etária dos $16<65$ anos passou de $40 \%$ em 1981 para $68 \%$ em 2003, como atesta a Tabela 1. Com base na Pesquisa Nacional por Amostra de Domicílios - PNAD de 2003, as mulheres representam 45\% da população ativa do país, $44 \%$ dos ocupados e $65 \%$ dos desempregados. A Tabela 2 revela que a relativa proporcionalidade que existia na condição de ocupados ou desocupados no início da década de 1980, quando eram as mulheres um terço dos ativos, dos ocupados e dos desempregados, desaparece vinte anos depois, estando as mulheres sobre-representadas em 2003 entre os desempregados.

Tabela 1

Taxa de Atividade segundo o Sexo

Brasil, 1981 e 2003*

\begin{tabular}{c|c|c|c|c}
\hline \multirow{2}{*}{} & \multicolumn{2}{|c|}{1981} & \multicolumn{2}{c}{2003} \\
\cline { 2 - 5 } & Masculino & Feminino & Masculino & Feminino \\
\hline Taxa de Atividade & $90 \%$ & $40 \%$ & $90 \%$ & $68 \%$ \\
\hline
\end{tabular}

Fontes: PNAD/IBGE, 1981 e 2003.

* Pessoas maiores de 16 e menores de 65 anos.

Tabela 2

População Economicamente Ativa

Brasil, 1981 e 2003*

\begin{tabular}{l|cc|cc}
\hline & \multicolumn{2}{|c|}{ 1981 } & \multicolumn{2}{c}{ 2003 } \\
\hline & Total & Mulheres (\%) & Total & Mulheres (\%) \\
\hline Ativos & 40.429 .814 & 31 & 88.441 .342 & 45 \\
Ocupados & 39.004 .705 & 31 & 82.330 .416 & 44 \\
Desocupados & 1.425 .109 & 34 & 6.110 .926 & 65 \\
\hline
\end{tabular}

Fontes: PNAD/IBGE, 1981 e 2003.

* Pessoas maiores de 16 e menores de 65 anos. 
Ao observar a evolução recente dos rendimentos do trabalho entre os sexos, constatamos que persiste a tendência da convergência enunciada acima, visto que em 2003 as mulheres receberam, em média, $84 \%$ do valor dos rendimentos masculinos, contra os $68 \%$ de 20 anos antes (Tabela 3). Não resta dúvida de que a progressão da redução do hiato salarial é muito lenta, e de que, mantido tal ritmo, o hiato salarial levará quase 80 anos para ser anulado.

Tabela 3

Diferencial de Rendimentos do Trabalho entre os Sexos

Brasil, 1981 e $2003^{*}$

\begin{tabular}{l|c|c}
\hline & $\mathbf{1 9 8 1}$ & $\mathbf{2 0 0 3}$ \\
\hline Diferencial & 0,68 & 0,84 \\
\hline
\end{tabular}

Fontes: PNAD/IBGE, 1981 e 2003.

* Pessoas maiores de 16 e menores de 65 anos; renda padronizada feminina dividida pela renda padronizada masculina.

A Tabela 4 mostra que a taxa de atividade das mulheres com filhos é praticamente idêntica à média, ou seja, da ordem de $67 \%$. Logo, o diferencial nas taxas de atividade entre mulheres com filhos (71\%) e sem filhos é pequeno, indicando que, ao contrário de outros países latino-americanos (por exemplo, o Chile), no Brasil a maternidade/maternagem não constitui um divisor de águas tão marcante a ponto de estabelecer padrões de atividade significativamente distintos para as mulheres. A convergência aí é grande.

Ocorre o inverso quando observamos os níveis de atividade feminina segundo o grau de escolaridade. Nesse caso, observa-se que a propensão à atividade cresce à medida que aumentam os anos de estudo. Como indica a Tabela 4, embora as mulheres brasileiras detentoras de diploma universitário registrem a mais alta taxa de atividade (88\%), porcentagem que é semelhante à taxa masculina com terceiro grau, constatou-se que, no período analisado (1981-2003), a taxa de atividade entre mulheres menos escolarizadas (ou seja, aquelas que não possuem nem mesmo o fundamental completo, isto é, os oito anos de escolaridade obrigatória) aumentou mais rapidamente. Portanto, a progressão da taxa de atividade feminina entre todos os grupos de escolaridade nos últimos 20 anos é indiscutível, reduzindo-se a dispersão patente 20 anos antes (de $35 \%$ para $74 \%$ ).

No período 1980-2000, a taxa de fecundidade total (TFT) manteve sua tendência de declínio, passando de 4,3 para 2,4 filhos por mulher. A PNAD de 2003 apontou uma TFT de 2,3 filhos por mulher e a estimati- 
Tabela 4

Taxa de Atividade Feminina - Brasil, 1981 e 2003*

\begin{tabular}{l|c|c}
\hline & $\mathbf{1 9 8 1}$ & $\mathbf{2 0 0 3}$ \\
\hline Total & $40 \%$ & $68 \%$ \\
Mulheres sem filhos & - & $71 \%$ \\
Mulheres com filhos & - & $67 \%$ \\
Mulheres com ensino fundamental incompleto & $35 \%$ & $60 \%$ \\
Mulheres com ensino fundamental completo & $51 \%$ & $72 \%$ \\
Mulheres com ensino secundário completo & $74 \%$ & $80 \%$ \\
Mulheres com ensino superior completo & - & $88 \%$ \\
\hline
\end{tabular}

Fontes: PNAD/IBGE, 1981 e 2003.

*Pessoas maiores de 15 e menores de 65 anos.

va é de que, durante a primeira década do século XXI, a taxa de fecundidade atinja o nível de reposição de aproximadamente 2,1 filhos por mulher em idade reprodutiva, número que representa a taxa em que uma geração de filhos repõe a geração de seus pais. Os dados do Instituto Brasileiro de Geografia e Estatística - IBGE para 2003 indicam um número médio de filhos por família de 1,4 filhos, contra a média de 1,8 de dez anos antes (IBGE, 2004b:179, Gráfico 5.3).

As famílias também mudaram (Sorj, 2004; Goldani e Verdugo Lazo, 2004), e multiplicaram-se os tipos de arranjos familiares. Segundo Goldani e Verdugo Lazo (2004), nos últimos 30 anos as famílias brasileiras quase triplicaram de número, o tamanho médio delas se reduziu (de 4,9 para 3,5 pessoas) e suas condições de vida melhoraram. No entanto, "a diversidade de modelos é sua característica mais notável" (idem:21). Segundo essas autoras, houve uma diminuição importante no número de famílias biparentais com filhos e um crescimento das famílias monoparentais (chefe sem cônjuge) com filhos; observa-se também uma progressão importante das famílias unipessoais.

\section{ARRANJOS FAMILIARES E DIFERENCIAIS DE GÊNERO POR CLASSE DE RENDA}

Em 2003, segundo o IBGE (Tabela 5), 10\% das famílias brasileiras eram constituídas por pessoas que moravam sozinhas (unipessoais); quase $15 \%$ compunha-se de casais sem filhos - logo, a quarta parte do total era de famílias sem presença de prole; $51 \%$ eram famílias nucleares com filhos; $18 \%$ eram chefiadas ${ }^{2}$ por mulheres sem cônjuges, porém com filhos; um resíduo de 6\% congregava outros arranjos (IBGE, 2004b:178, Gráficos 5.1 e 5.2). O percentual de famílias com pessoa de referência do sexo feminino era de 28,8\% em 2003, contra $16 \%$ em 1981. Desse total de 15,3 milhões de famílias chefiadas por mulheres, quase dois terços eram monoparentais com filhos. As famílias monoparentais 
cuja pessoa de referência do sexo masculino eram em número tão reduzido que não tinham significância estatística (menos de 1\%).

Tabela 5

Distribuição das Famílias segundo o Tipo de Família e o Sexo do Chefe - Brasil, 2003

\begin{tabular}{l|c|c|c}
\hline & Masculino & Feminino & Total \\
\hline Unipessoal & $6,9 \%$ & $17,5 \%$ & $9,9 \%$ \\
Casal sem filhos & $19,0 \%$ & $2,8 \%$ & $14,4 \%$ \\
Casal com filhos & $69,0 \%$ & $8,1 \%$ & $51,5 \%$ \\
Mãe sem cônjuge com filhos & $0,0 \%$ & $62,8 \%$ & $18,1 \%$ \\
Outros tipos & $5,1 \%$ & $8,8 \%$ & $6,1 \%$ \\
\hline Total & $\mathbf{3 8 . 2 6 1 . 4 0 5}$ & $\mathbf{1 5 . 4 7 7 . 8 2 3}$ & $\mathbf{5 3 . 7 3 9 . 2 2 8}$ \\
\hline
\end{tabular}

Fonte: PNAD/IBGE, 2003.

Supõe-se que as idades médias de homens e mulheres na condição de pessoa de referência nos arranjos familiares acima classificados variem significativamente. Conforme expressa a Tabela 6, os chefes de famílias sem filhos (unipessoais ou casais) eram, em média, mais velhos (acima dos 50 anos) do que aqueles à frente de famílias com filhos (na faixa dos 42-45 anos). As mulheres que se declararam chefes tinham, em média, 48 anos, ao passo que os homens tinham 45 anos. Esse diferencial pouco significativo de 3 anos é bem maior no caso das famílias unipessoais (12 anos). Nas tabelas subseqüentes, em que a renda foi desagregada por decis, averiguamos que a idade média das pessoas de referência na família aumenta à medida que aumenta a renda familiar. Conseqüentemente, os adultos no auge da sua capacidade produtiva (30-45 anos), responsáveis pela criação e educação de dependentes menores de idade, seriam mais vulneráveis, porque situados na cauda inferior da distribuição.

Tabela 6

Idade Média dos Chefes de Família segundo o Tipo de Família e o Sexo do Chefe - Brasil, 2003

\begin{tabular}{l|c|c|c}
\hline & Masculino & Feminino & Total \\
\hline Unipessoal & 47 & 59 & 53 \\
Casal sem filhos & 50 & 46 & 50 \\
Casal com filhos & 43 & 40 & 42 \\
Mãe sem cônjuge com filhos & 45 & 45 & 51 \\
Outros tipos & 47 & 56 & $\mathbf{4 6}$ \\
\hline Total & $\mathbf{4 5}$ & $\mathbf{4 8}$ & \\
\hline
\end{tabular}

Fonte: PNAD/IBGE, 2003. 
Outro aspecto valioso a ser contemplado ao se tecerem perfis de cada sexo - sejam eles relativos à inserção produtiva, ao grau de proteção previdenciária ou a outros aspectos - diz respeito à situação de cada sexo ao longo da distribuição de renda. Com efeito, se considerarmos que o grupo "mulheres" torna-se a cada dia mais heterogêneo, em conseqüência dos níveis crescentes de atividade e ocupação femininas - os quais provavelmente acentuam o padrão de desigualdade prevalecente na sociedade entre as mulheres -, cabe-nos, então, detalhar por classe de renda suas características, pois o agregado oculta, nas médias, as especificidades ditadas pelo maior ou menor grau de destituição ou inclusão. Para tanto, resolvemos desagregar em decis os dados construídos segundo o tipo de família, sendo a ordenação feita com base na renda familiar per capita ${ }^{3}$.

Assim, a Tabela 7 apresenta a distribuição das famílias com base nas categorias consagradas pelo IBGE para 2003, mas desagregando-as consecutivamente segundo a classe de renda. Vemos que as famílias com filhos são amplamente majoritárias (mais de 75\%) nos seis primeiros decis e que sua participação diminui rapidamente a partir do sétimo decil. Isso mostra o quão fundamentais poderiam ser aquelas políticas

Tabela 7

Distribuição das Famílias segundo o Tipo de Família, a Chefia e o Decil de Renda Familiar Per Capita

Brasil, 2003*

\begin{tabular}{l|c|c|c|c|c|c}
\hline & Unipessoal & $\begin{array}{c}\text { Casal sem } \\
\text { filhos }\end{array}$ & $\begin{array}{c}\text { Casal com } \\
\text { filhos }\end{array}$ & $\begin{array}{c}\text { Mãe sem } \\
\text { cônjuge }\end{array}$ & Outras & Total \\
\hline $1^{\circ}$ & $6 \%$ & $5 \%$ & $48 \%$ & $37 \%$ & $4 \%$ & 4.326 .670 \\
$\mathbf{2}^{\circ}$ & $2 \%$ & $4 \%$ & $71 \%$ & $20 \%$ & $3 \%$ & 3.619 .913 \\
$\mathbf{3}^{\circ}$ & $2 \%$ & $6 \%$ & $67 \%$ & $20 \%$ & $5 \%$ & $\mathbf{4 . 1 0 4 . 8 8 4}$ \\
$\mathbf{4}^{\circ}$ & $2 \%$ & $12 \%$ & $55 \%$ & $23 \%$ & $8 \%$ & 4.591 .632 \\
$\mathbf{5}^{\circ}$ & $2 \%$ & $12 \%$ & $60 \%$ & $19 \%$ & $6 \%$ & $\mathbf{4 . 7 4 0 . 6 3 4}$ \\
$\mathbf{6}^{\circ}$ & $3 \%$ & $12 \%$ & $61 \%$ & $18 \%$ & $6 \%$ & $\mathbf{5 . 0 0 1 . 4 8 5}$ \\
$\mathbf{7}^{\circ}$ & $22 \%$ & $20 \%$ & $37 \%$ & $14 \%$ & $7 \%$ & $\mathbf{6 . 7 6 7 . 5 8 1}$ \\
$\mathbf{8}^{\circ}$ & $9 \%$ & $18 \%$ & $50 \%$ & $15 \%$ & $7 \%$ & $\mathbf{6 . 0 4 1 . 4 9 5}$ \\
$\mathbf{9}^{\circ}$ & $16 \%$ & $20 \%$ & $44 \%$ & $13 \%$ & $7 \%$ & $\mathbf{6 . 6 4 4 . 5 2 6}$ \\
$\mathbf{1 0}^{\circ}$ & $20 \%$ & $22 \%$ & $41 \%$ & $11 \%$ & $7 \%$ & $\mathbf{6 . 8 4 0 . 9 8 3}$ \\
\hline Total & $\mathbf{1 0 \%}$ & $\mathbf{1 4 \%}$ & $\mathbf{5 1 \%}$ & $\mathbf{1 8 \%}$ & $\mathbf{6 \%}$ & $\mathbf{5 2 . 6 8 0 . 0 7 3}$ \\
\hline
\end{tabular}

Fonte: PNAD/IBGE, 2003.

* Foram excluídos os casos de missings na renda das famílias e no tipo de família. 
voltadas para as famílias com filhos se bem calibradas para promover a redistribuição de renda entre ricos e pobres no país. Elas permitiriam compensar os custos diretos e indiretos com a educação das crianças e reduzir o custo de oportunidade do trabalho infantil, que permanece elevado nas camadas mais pobres. No entanto, o Brasil jamais formulou políticas universais voltadas para a família, e os benefícios concedidos pela legislação trabalhista focalizam prioritariamente os direitos reprodutivos das mulheres ${ }^{4}$ (Sorj, 2004), ou atendem a um grupo reduzido de trabalhadores formais que preenchem os critérios estabelecidos para recebimento do salário-família.

Essa mesma tabela desagregada por sexo da pessoa de referência (Tabelas 8 e 9) indica que inexiste um padrão familiar de gênero ao longo da distribuição, exceção feita às famílias monoparentais - arranjo esse exclusivamente feminino ${ }^{5}$, e cuja categoria, portanto, podemos considerar como uma categoria de gênero. Ou seja, conforme mostram as Tabelas 8 e 9, tanto as famílias unipessoais quanto as famílias constituídas por casais sem filhos estão concentradas na faixa dos $40 \%$ mais ricos, sejam elas chefiadas por homens ( $81 \%$ e $62 \%$, respectivamente) ou por mulheres (90\% e 72\%). Observe-se que essa concentração é ainda mais acentuada para as mulheres. No caso das famílias biparentais com filhos, e independentemente do sexo da pessoa de referência, a distribuição é relativamente isômere ao longo dos decis. Já as famílias monoparentais chefiadas por mulheres com filhos revelam um padrão de distribuição distinto, pois $17 \%$ encontram-se no primeiro decil, muito embora os restantes $83 \%$ estejam, de fato, dispostos em proporções mais ou menos semelhantes ao longo da curva.

Algumas conclusões derivam da leitura dessas tabelas: primeiramente, as famílias monoparentais com chefia feminina e prole não podem ser interpretadas exclusivamente como manifestação da pobreza, pois revelam um fenômeno de proporções bem mais amplas, por estarem representadas em todas as classes de renda e por esse tipo de arranjo implicar um ônus suplementar para todas as mulheres. Em segundo lugar, a chefia feminina nem sempre expressa alta vulnerabilidade, dado que, nos arranjos familiares sem a presença de filhos, sua freqüência é mais elevada nos décimos superiores da distribuição. Finalmente, entre os $10 \%$ mais pobres, o número de famílias chefiadas por homens e mulheres é mais ou menos equivalente, embora expresse situações absolutamente distintas, uma vez que, no caso das mulheres, essas estão sozinhas diante dos desafios profissionais e familiares. 
Tabela 8

Distribuição das Famílias com Chefes Homens segundo o Tipo de Família e o Decil de Renda Familiar Per Capita - Brasil, 2003*

\begin{tabular}{c|cc|cc|cc|cc}
\hline & Unipessoal & $\%$ & $\begin{array}{c}\text { Casal sem } \\
\text { filhos }\end{array}$ & $\%$ & $\begin{array}{l}\text { Casal com } \\
\text { filhos }\end{array}$ & $\%$ & Outras & $\%$ \\
\hline $\mathbf{1}^{\circ}$ & 166.498 & 7 & 221.362 & 3 & 1.953 .709 & 8 & 119.103 & 6 \\
$\mathbf{2}^{\circ}$ & 39.654 & 2 & 140.828 & 2 & 2.454 .300 & 10 & 70.547 & 4 \\
$\mathbf{3}^{\circ}$ & 63.144 & 2 & 224.975 & 3 & 2.613 .397 & 10 & 109.866 & 6 \\
$\mathbf{4}^{\circ}$ & 40.504 & 2 & 530.520 & 8 & 2.401 .805 & 9 & 179.354 & 10 \\
$\mathbf{5}^{\circ}$ & 65.024 & 3 & 525.683 & 7 & 2.700 .028 & 11 & 174.182 & 9 \\
$\mathbf{6}^{\circ}$ & 100.193 & 4 & 551.551 & 8 & 2.879 .650 & 11 & 186.926 & 10 \\
$\mathbf{7}^{\circ}$ & 611.917 & 24 & 1.238 .295 & 18 & 2.365 .367 & 9 & 258.051 & 14 \\
$\mathbf{8}^{\circ}$ & 311.043 & 12 & 1.016 .200 & 14 & 2.816 .554 & 11 & 259.855 & 14 \\
$\mathbf{9}^{\circ}$ & 488.810 & 19 & 1.233 .154 & 17 & 2.748 .386 & 11 & 247.940 & 13 \\
$\mathbf{1 0}^{\circ}$ & 665.094 & 26 & 1.371 .076 & 19 & 2.652 .479 & 10 & 257.724 & 14 \\
\hline Total & $\mathbf{2 . 5 8 1 . 3 6 9}$ & $\mathbf{1 0 0}$ & $\mathbf{7 . 1 3 4 . 6 1 1}$ & $\mathbf{1 0 0}$ & $\mathbf{2 5 . 8 8 1 . 0 7 8}$ & $\mathbf{1 0 0}$ & $\mathbf{1 . 8 8 5 . 3 8 2}$ & $\mathbf{1 0 0}$ \\
\hline
\end{tabular}

Fonte: PNAD/IBGE, 2003.

* Ordenação segundo a renda familiar per capita.

Tabela 9

Distribuição das Famílias com Chefes Mulheres segundo o Tipo de Família e o Decil de Renda Familiar Per Capita - Brasil, 2003*

\begin{tabular}{c|cc|cc|cc|cc|cc}
\hline & Unipessoal & $\%$ & $\begin{array}{c}\text { Casal sem } \\
\text { filhos }\end{array}$ & $\%$ & $\begin{array}{c}\text { Casal com } \\
\text { filhos }\end{array}$ & $\%$ & $\begin{array}{c}\text { Mãe com } \\
\text { filhos }\end{array}$ & $\%$ & Outras & $\%$ \\
\hline $1^{\circ}$ & 80.757 & 3 & 12.090 & 3 & 82.518 & 7 & 1.598 .378 & 17 & 45.506 & 3 \\
$\mathbf{2}^{\circ}$ & 24.857 & 1 & 8.141 & 2 & 88.603 & 7 & 716.291 & 8 & 38.209 & 3 \\
$\mathbf{3}^{\circ}$ & 27.833 & 1 & 9.915 & 2 & 109.242 & 9 & 826.740 & 9 & 73.678 & 6 \\
$\mathbf{4}^{\circ}$ & 28.659 & 1 & 30.177 & 7 & 112.835 & 9 & 1.031 .257 & 11 & 184.385 & 14 \\
$\mathbf{5}^{\circ}$ & 38.657 & 1 & 24.048 & 6 & 132.638 & 11 & 909.300 & 10 & 116.414 & 9 \\
$\mathbf{6}^{\circ}$ & 70.491 & 3 & 33.800 & 8 & 137.902 & 11 & 872.499 & 9 & 110.073 & 8 \\
$\mathbf{7}^{\circ}$ & 873.008 & 33 & 73.814 & 18 & 105.625 & 9 & 963.932 & 10 & 201.015 & 15 \\
$\mathbf{8}^{\circ}$ & 250.018 & 9 & 63.898 & 15 & 155.838 & 13 & 921.734 & 10 & 175.627 & 13 \\
$\mathbf{9}^{\circ}$ & 577.368 & 22 & 65.044 & 16 & 155.964 & 13 & 869.742 & 9 & 179.392 & 14 \\
$\mathbf{1 0}^{\circ}$ & 674.866 & 26 & 97.366 & 23 & 123.350 & 10 & 729.618 & 8 & 187.144 & 14 \\
\hline Total $^{\circ}$ & $\mathbf{2 . 6 7 6 . 6 8 8}$ & $\mathbf{1 0 0}$ & $\mathbf{4 2 3 . 4 9 0}$ & $\mathbf{1 0 0}$ & $\mathbf{1 . 2 1 9 . 9 7 6}$ & $\mathbf{1 0 0}$ & $\mathbf{9 . 5 5 0 . 3 5 9}$ & $\mathbf{1 0 0}$ & $\mathbf{1 . 3 2 6 . 4 9 0}$ & $\mathbf{1 0 0}$ \\
\hline
\end{tabular}

Fonte: PNAD/IBGE, 2003.

* Ordenação segundo a renda familiar per capita.

Se nos detivermos agora na Tabela 10, vamos constatar, ao fixar os seis primeiros décimos da distribuição, que pelo menos $70 \%$ das famílias cuja pessoa de referência é do sexo feminino são arranjos monoparentais com filhos, percentual esse, aliás, acima da média de $63 \%$ observada para essa categoria no conjunto da população. Em contrapartida, os 
arranjos unipessoais femininos têm peso destacado nas faixas de renda elevadas, mais precisamente entre os $40 \%$ mais ricos. As mulheres declaram-se pessoa de referência quase sempre na ausência da figura masculina (81\% são mães com filhos sem cônjuge ou constituem famílias unipessoais). Logo, chefia feminina significa estar sozinha. Já os homens, indica a Tabela 11, quando tidos como pessoa de referência, concentram-se em estruturas familiares onde existe a relação de subalternidade patriarcal com a figura da cônjuge ( $88 \%$ ). Enquanto as famílias chefiadas por mulheres se distribuem em números absolutos de forma homogênea entre decis, aquelas chefiadas por homens aumentam à medida que se sobe na curva da distribuição de renda.

Tabela 10

Distribuição das Famílias com Chefes Mulheres segundo o Tipo de Família e o Decil de Renda Familiar Per Capita - Brasil, 2003*

\begin{tabular}{c|c|c|c|c|c|c}
\hline & Unipessoal & $\begin{array}{c}\text { Casal sem } \\
\text { filhos }\end{array}$ & $\begin{array}{c}\text { Casal com } \\
\text { filhos }\end{array}$ & $\begin{array}{c}\text { Mãe com } \\
\text { filhos }\end{array}$ & Outras & Total \\
\hline $1^{\circ}$ & $4 \%$ & $1 \%$ & $5 \%$ & $88 \%$ & $3 \%$ & 1.840 .184 \\
$\mathbf{2}^{\circ}$ & $3 \%$ & $1 \%$ & $10 \%$ & $82 \%$ & $4 \%$ & 886.156 \\
$\mathbf{3}^{\circ}$ & $3 \%$ & $1 \%$ & $10 \%$ & $79 \%$ & $7 \%$ & 1.059 .827 \\
$\mathbf{4}^{\circ}$ & $2 \%$ & $2 \%$ & $8 \%$ & $74 \%$ & $13 \%$ & 1.403 .475 \\
$\mathbf{5}^{\circ}$ & $3 \%$ & $2 \%$ & $11 \%$ & $74 \%$ & $10 \%$ & 1.235 .427 \\
$\mathbf{6}^{\circ}$ & $6 \%$ & $3 \%$ & $11 \%$ & $71 \%$ & $9 \%$ & 1.239 .327 \\
$\mathbf{7}^{\circ}$ & $39 \%$ & $3 \%$ & $5 \%$ & $43 \%$ & $9 \%$ & 2.242 .590 \\
$\mathbf{8}^{\circ}$ & $16 \%$ & $4 \%$ & $10 \%$ & $59 \%$ & $11 \%$ & 1.585 .892 \\
$\mathbf{9}^{\circ}$ & $31 \%$ & $4 \%$ & $8 \%$ & $47 \%$ & $10 \%$ & 1.869 .636 \\
$\mathbf{1 0}^{\circ}$ & $37 \%$ & $5 \%$ & $7 \%$ & $40 \%$ & $10 \%$ & 1.834 .489 \\
\hline Total $^{\circ}$ & $\mathbf{1 8 \%}$ & $\mathbf{3 \%}$ & $\mathbf{8 \%}$ & $\mathbf{6 3 \%}$ & $\mathbf{9 \%}$ & $\mathbf{1 5 . 1 9 7 . 0 0 3}$ \\
\hline
\end{tabular}

Fonte: PNAD/IBGE, 2003.

* Ordenação segundo a renda familiar per capita.

Tomando agora as famílias com presença de filhos na faixa etária de 0-16 anos, podemos observar, na Tabela 12, que dois terços das crianças se encontram na metade mais pobre da população e que essa proporção varia inversamente à renda (Lavinas, 2004) nas três categorias familiares observadas. Cabe assinalar que as famílias monoparentais com chefia feminina detêm apenas 19\% do universo de crianças referido, pois três quartos vivem em arranjos nucleares. 
Tabela 11

Distribuição das Famílias com Chefes Homens segundo o Tipo de Família e o Decil de Renda Familiar Per Capita - Brasil, 2003*

\begin{tabular}{c|c|c|c|c|c}
\hline & Unipessoal & $\begin{array}{c}\text { Casal sem } \\
\text { filhos }\end{array}$ & $\begin{array}{c}\text { Casal com } \\
\text { filhos }\end{array}$ & Outras & Total \\
\hline $1^{\circ}$ & $7 \%$ & $9 \%$ & $79 \%$ & $5 \%$ & 2.486 .486 \\
$\mathbf{2}^{\circ}$ & $1 \%$ & $5 \%$ & $91 \%$ & $3 \%$ & 2.733 .757 \\
$\mathbf{3}^{\circ}$ & $2 \%$ & $7 \%$ & $87 \%$ & $4 \%$ & 3.045 .057 \\
$\mathbf{4}^{\circ}$ & $1 \%$ & $17 \%$ & $76 \%$ & $6 \%$ & 3.188 .157 \\
$\mathbf{5}^{\circ}$ & $2 \%$ & $15 \%$ & $78 \%$ & $5 \%$ & 3.505 .207 \\
$\mathbf{6}^{\circ}$ & $3 \%$ & $15 \%$ & $77 \%$ & $5 \%$ & 3.762 .158 \\
$\mathbf{7}^{\circ}$ & $14 \%$ & $28 \%$ & $53 \%$ & $6 \%$ & 4.525 .261 \\
$\mathbf{8}^{\circ}$ & $7 \%$ & $23 \%$ & $64 \%$ & $6 \%$ & 4.455 .603 \\
$\mathbf{9}^{\circ}$ & $10 \%$ & $26 \%$ & $58 \%$ & $5 \%$ & 4.774 .890 \\
$\mathbf{1 0}^{\circ}$ & $13 \%$ & $\mathbf{2 8 \%}$ & $54 \%$ & $5 \%$ & 5.006 .494 \\
\hline Total & $\mathbf{7 \%}$ & $\mathbf{1 9 \%}$ & $\mathbf{6 9 \%}$ & $\mathbf{5 \%}$ & 37.483 .070 \\
\hline
\end{tabular}

Fonte: PNAD/IBGE, 2003.

* Ordenação segundo a renda familiar per capita.

É senso comum que a taxa de atividade feminina pode ser afetada na sua magnitude e evolução pela presença dos filhos, muito embora também se saiba que, no agregado, o casamento ou a maternidade e os cuidados com crianças e idosos já não provocam, como há décadas, elevação da inatividade nas coortes mais jovens. Seu efeito mais contundente é reduzir o leque de oportunidades de emprego e galvanizar o acesso a ocupações precárias e menos qualificadas, que oferecem jornadas de trabalho mais reduzidas e permitem compatibilizar trabalho e responsabilidades familiares. Pesquisa recente realizada por Sorj (2004) revelou que as mulheres trabalhadoras pobres com crianças pequenas (com idades variando de 0 a 6 anos) freqüentando creches auferiam rendimentos do trabalho superiores àquelas, igualmente pobres e ocupadas, cujos filhos da mesma idade não dispunham de opções externas de guarda. Sorj foi mais longe e constatou que, ao se comparar grupos de domicílios segundo a renda per capita, observa-se que, para os $25 \%$ mais pobres, ter crianças de 4-6 anos freqüentando a pré-escola eleva o salário da mãe em $35 \%$, enquanto para os $25 \%$ mais ricos tal aumento é de apenas $14 \%$ (idem).

A Tabela 13 abaixo reitera aspectos enfatizados por Sorj (idem). Mostra que somente $37 \%$ das crianças brasileiras na faixa de 0 a 6 anos freqüentam creches ou a pré-escola. As famílias chefiadas por mulheres sem a 
presença de cônjuge parecem ter acesso mais efetivo a esse tipo de equipamento do que as famílias nucleares biparentais, em todas as classes de renda, por força das circunstâncias. Tendo que assumir sozinha a responsabilidade financeira de cuidar de uma família, não resta outra alternativa às mulheres chefes senão encontrar meios de guarda das crianças. O acesso à creche aumenta com a renda, mais que dobrando entre o primeiro e o último décimo da distribuição, o que confirma ser a provisão desse serviço não um direito desmercantilizado, mas um serviço privado. Há que recordar que, estando a maioria das crianças nos primeiros décimos da distribuição (Tabela 12), são ainda mais adversas as oportunidades de inserção ocupacional das mulheres mais pobres. O ratio (número de vagas demandada em creche por mulher adulta) permanece, portanto, elevado.

Tabela 12

Distribuição das Crianças de 0 a 16 Anos segundo o Tipo de Família e o Decil de Renda Familiar Per Capita - Brasil, 2003*

\begin{tabular}{c|c|c|c|c}
\hline & Casal com filhos & Mãe com filhos & Outras & Total \\
\hline $\mathbf{1}^{\circ}$ & $65 \%$ & $32 \%$ & $2 \%$ & 8.690 .638 \\
$\mathbf{2}^{\circ}$ & $79 \%$ & $18 \%$ & $2 \%$ & 8.132 .569 \\
$\mathbf{3}^{\circ}$ & $76 \%$ & $19 \%$ & $3 \%$ & 6.969 .920 \\
$\mathbf{4}^{\circ}$ & $75 \%$ & $19 \%$ & $5 \%$ & 6.076 .945 \\
$\mathbf{5}^{\circ}$ & $77 \%$ & $17 \%$ & $4 \%$ & 5.657 .218 \\
$\mathbf{6}^{\circ}$ & $79 \%$ & $16 \%$ & $4 \%$ & 4.984 .753 \\
$\mathbf{7}^{\circ}$ & $\mathbf{7 9 \%}$ & $15 \%$ & $4 \%$ & 3.706 .954 \\
$\mathbf{8}^{\circ}$ & $82 \%$ & $13 \%$ & $3 \%$ & 3.748 .127 \\
$\mathbf{9}^{\circ}$ & $84 \%$ & $12 \%$ & $2 \%$ & 3.337 .766 \\
$\mathbf{1 0}^{\circ}$ & $86 \%$ & $11 \%$ & $2 \%$ & 2.779 .702 \\
\hline Total & $\mathbf{7 6 \%}$ & $\mathbf{1 9 \%}$ & $\mathbf{3 \%}$ & $\mathbf{5 4 . 0 8 4 . 6 9 2}$ \\
\hline
\end{tabular}

Fonte: PNAD/IBGE, 2003.

* Ordenação segundo a renda familiar per capita; foram excluídas as crianças sem classificação familiar.

Os dados da PNAD indicam que somente $2 \%$ dos trabalhadores ${ }^{6}$ de ambos os sexos declararam receber em 2003 algum auxílio financeiro para compensar despesas com creche ou educação. Já na rubrica transportes, são contemplados $37 \%$ dos trabalhadores do sexo feminino e $35 \%$ dos trabalhadores do sexo masculino. Isso demonstra a pouca atenção também no plano dos auxílios trabalhistas a questões ligadas ao que se convencionou chamar de maternagem, de forma a facilitar a conciliação do tempo de trabalho com os cuidados com a família. $\mathrm{Na}$ ausência de políticas públicas conseqüentes, a grande maioria das mulheres com filhos pequenos tem de buscar soluções individuais e privadas para a guarda das suas crianças. Mesmo para as classes de maior 
poder aquisitivo não existem deduções fiscais, no imposto de renda de pessoa física, que permitam compensar gastos elevados com creche e pré-escola.

Tabela 13

Percentual de Crianças de 0 a 6 Anos que Freqüentam Creche ou Escola segundo o Tipo de Família e o Decil de Renda Familiar Per Capita - Brasil, 2003*

\begin{tabular}{c|c|c|c|c}
\hline & Casal com filhos & Mãe com filhos & Outras & Total \\
\hline $1^{\circ}$ & 29 & 29 & 32 & 29 \\
$\mathbf{2}^{\mathbf{0}}$ & 32 & 39 & 43 & 33 \\
$\mathbf{3}^{\mathbf{0}}$ & 31 & 43 & 48 & 34 \\
$\mathbf{4}^{\mathbf{0}}$ & 34 & 42 & 44 & 35 \\
$\mathbf{5}^{\mathbf{0}}$ & 36 & 45 & 50 & 38 \\
$\mathbf{6}^{\mathbf{0}}$ & 40 & 48 & 53 & 41 \\
$\mathbf{7}^{\mathbf{0}}$ & 42 & 51 & 51 & 43 \\
$\mathbf{8}^{\mathbf{0}}$ & 46 & 58 & 56 & 48 \\
$\mathbf{9}^{\mathbf{0}}$ & 51 & 68 & 73 & 53 \\
$\mathbf{1 0}^{\mathbf{0}}$ & 56 & 69 & 59 & 57 \\
\hline Total & 37 & 39 & 47 & 37 \\
\hline
\end{tabular}

Fonte: PNAD/IBGE, 2003.

* Ordenação segundo a renda familiar per capita; foram excluídas as crianças sem classificação familiar.

Controlada por faixa etária, a curva de atividade feminina assemelha-se cada vez mais na sua evolução à curva de atividade masculina, a despeito de os patamares registrados serem ainda bastante díspares. A Tabela 14 nos mostra justamente que, na posição de pessoa de referência na família, as mulheres registram taxas de atividade mais elevadas (em torno de $76 \%$ ) do que na condição de cônjuges (aproximadamente $65 \%$ ), diferencial inexistente quando aplicado aos homens. Aparentemente, a subalternidade do lugar de cônjuge mostra-se mais correlacionada a taxas de atividade mais baixas do que propriamente à prole.

Tabela 14

Taxa de Atividade dos Chefes e Cônjuges segundo o Tipo de Família e o Sexo - Brasil, 2003*

\begin{tabular}{l|cc|cc}
\hline & \multicolumn{2}{|c|}{ Chefes } & \multicolumn{2}{c}{ Cônjuges } \\
\hline & Masculino & Feminino & Masculino & Feminino \\
\hline Unipessoal & $90 \%$ & $72 \%$ & & \\
Casal sem filhos & $91 \%$ & $77 \%$ & $89 \%$ & $66 \%$ \\
Casal com filhos & $95 \%$ & $77 \%$ & $92 \%$ & $64 \%$ \\
Mãe com filhos & & $76 \%$ & & \\
\hline
\end{tabular}

Fonte: PNAD/IBGE, 2003.

* Pessoas maiores de 16 e menores de 65 anos. 
Da mesma maneira, a análise da Tabela 15 demonstra que a jornada semanal de trabalho remunerado das mulheres cônjuges é menor do que aquela declarada pelas mulheres chefes, o que novamente não ocorre no caso dos homens, cujo padrão uniforme parece ser independente da tal posição de subalternidade no arranjo familiar.

Tabela 15

Número Médio de Horas Trabalhadas na Semana dos Chefes e Cônjuges segundo o Tipo de Família e o Sexo - Brasil, 2003*

\begin{tabular}{l|cc|cc}
\hline & \multicolumn{2}{|c|}{ Chefes } & \multicolumn{2}{c}{ Cônjuges } \\
\hline & Masculino & Feminino & Masculino & Feminino \\
\hline Unipessoal & 45,8 & 39,8 & & 36,4 \\
Casal sem filhos & 46,7 & 40,3 & 45,6 & 34,6 \\
Casal com filhos & 47,8 & 40,1 & 47,2 & \\
Mãe com filhos & \multicolumn{3}{|c}{39,1} & \\
\hline
\end{tabular}

Fonte: PNAD/IBGE, 2003.

* Pessoas maiores de 16 e menores de 65 anos.

Se desagregarmos tais informações pelos decis da distribuição (Tabela 16), veremos que, no caso das mulheres chefes a taxa de atividade varia de $75 \%$ a $81 \%$, dependendo da classe de renda. A exceção que confirma

Tabela 16

Taxa de Atividade segundo o Sexo, a Chefia e o Decil de Renda Familiar Per Capita Brasil, 2003*

\begin{tabular}{c|cc|cc}
\hline & \multicolumn{3}{|c|}{ Chefes } & \multicolumn{2}{c}{ Cônjuges } \\
\hline & Masculino & Feminino & Masculino & Feminino \\
\hline $\mathbf{1}^{\circ}$ & $96 \%$ & $69 \%$ & $88 \%$ & $61 \%$ \\
$\mathbf{2}^{\circ}$ & $97 \%$ & $81 \%$ & $90 \%$ & $58 \%$ \\
$\mathbf{3}^{\circ}$ & $97 \%$ & $77 \%$ & $89 \%$ & $58 \%$ \\
$\mathbf{4}^{\circ}$ & $94 \%$ & $75 \%$ & $92 \%$ & $61 \%$ \\
$\mathbf{5}^{\circ}$ & $96 \%$ & $78 \%$ & $91 \%$ & $64 \%$ \\
$\mathbf{6}^{\circ}$ & $95 \%$ & $79 \%$ & $93 \%$ & $67 \%$ \\
$\mathbf{7}^{\circ}$ & $92 \%$ & $69 \%$ & $90 \%$ & $66 \%$ \\
$\mathbf{8}^{\circ}$ & $93 \%$ & $77 \%$ & $93 \%$ & $69 \%$ \\
$\mathbf{9}^{\circ}$ & $92 \%$ & $78 \%$ & $93 \%$ & $68 \%$ \\
$\mathbf{1 0}^{\circ}$ & $92 \%$ & $78 \%$ & $93 \%$ & $70 \%$ \\
\hline Total & $94 \%$ & $\mathbf{7 6 \%}$ & $\mathbf{9 2 \%}$ & $\mathbf{6 5 \%}$ \\
\hline
\end{tabular}

Fonte: PNAD/IBGE, 2003.

* Pessoas maiores de 16 e menores de 65 anos. 
a regra é a faixa dos $10 \%$ mais pobres, que foge a esse intervalo, registrando um patamar inferior (69\%). No caso dos cônjuges, observa-se um comportamento distinto: a taxa de atividade feminina tende a aumentar à medida que se galgam os decis da distribuição, oscilando mais ao longo da curva, mas permanecendo em todas as classes de renda menor do que a observada entre as mulheres chefes. Em média, somente $65 \%$ das cônjuges estão em atividade contra $76 \%$ das chefes. $O$ contraponto homem-mulher na posição de cônjuge indica, de modo geral, diferenciais de atividades mais desfavoráveis às mulheres do que aqueles verificados na comparação de ambos os sexos na condição de pessoa de referência.

Como seria de se esperar, o número médio de horas trabalhadas por semana pelas mulheres é sistematicamente menor se cônjuges vis-à-vis às que se declararam chefes ( 34 horas e 39 horas, respectivamente). Tal como verificado no caso da atividade, a jornada semanal das mulheres tende a aumentar consistentemente ao longo da distribuição de renda, como revela a Tabela 17, contribuindo para reduzir conseqüentemente o diferencial de horário entre os sexos nas classes de renda mais altas.

Tabela 17

Número Médio de Horas Trabalhadas na Semana segundo o Sexo, a Chefia e o Decil de Renda Familiar Per Capita - Brasil, 2003*

\begin{tabular}{c|cc|cc}
\hline & \multicolumn{3}{|c|}{ Chefes } & \multicolumn{2}{c}{ Cônjuges } \\
\hline & Masculino & Feminino & Masculino & Feminino \\
\hline $\mathbf{1}^{\circ}$ & 42,62 & 29,83 & 40,41 & 22,67 \\
$\mathbf{2}^{\mathbf{0}}$ & 46,51 & 35,55 & 45,08 & 26,71 \\
$\mathbf{3}^{\mathbf{0}}$ & 47,51 & 37,89 & 46,70 & 28,74 \\
$\mathbf{4}^{\mathbf{0}}$ & 47,67 & 39,21 & 47,22 & 31,76 \\
$\mathbf{5}^{\mathbf{0}}$ & 47,63 & 39,60 & 47,04 & 33,63 \\
$\mathbf{6}^{\mathbf{0}}$ & 47,73 & 40,67 & 46,97 & 35,26 \\
$\mathbf{7}^{\mathbf{0}}$ & 47,68 & 39,47 & 46,63 & 36,61 \\
$\mathbf{8}^{\mathbf{0}}$ & 48,19 & 39,96 & 48,10 & 38,19 \\
$\mathbf{9}^{\mathbf{0}}$ & 47,82 & 41,65 & 47,45 & 39,43 \\
$\mathbf{1 0}^{\mathbf{0}}$ & 47,69 & 42,40 & 46,37 & 39,69 \\
\hline Total & 47,41 & 39,35 & 46,76 & 34,93 \\
\hline
\end{tabular}

Fonte: PNAD/IBGE, 2003.

* Ordenação segundo a renda familiar per capita.

Finalmente, cabe estimar qual o hiato salarial entre homens e mulheres segundo a tipologia familiar adotada, a posição na distribuição e a con- 
dição de referência, o que consta da Tabela 18. Nesse quesito, as surpresas não são poucas. Inexiste hiato de rendimento entre os sexos nos quatro primeiros decis da distribuição, independentemente da posição de referência da mulher, se chefe ou cônjuge. Mais impressionante ainda é constatar que a reversão do hiato salarial entre os sexos na faixa de renda mais pobre é favorável em $30 \%$ às mulheres chefes. O hiato desfavorável às mulheres chefes se acentua a partir do quarto decil. $\mathrm{O}$ aumento do diferencial de rendimentos entre homens e mulheres, em ambas as posições de referência, observa-se na metade superior da curva de distribuição, acentuando-se ainda mais nos dois últimos decis (Tabela 18), ou seja, em posições nas quais as mulheres são detentoras de maior grau de escolaridade, o que poderia significar bloqueio da mobilidade funcional, em razão de discriminações sexistas no mercado de trabalho (a ponta superior da pirâmide ocupacional seria de difícil acesso às mulheres, qualquer que seja sua dotação de capital humano). Entre os mais pobres, o hiato salarial de gênero está desaparecendo, o que demanda investigações suplementares para explicar as causas de uma tal reversão de tendência tão abrupta.

Tabela 18

Hiato de Rendimento Médio Padronizado entre os Sexos segundo o Sexo, a Chefia e o Decil de Renda Familiar Per Capita - Brasil, 2003*

\begin{tabular}{c|c|c}
\hline & Chefes & Cônjuges \\
\hline $\mathbf{1}^{\circ}$ & 1,3 & 1 \\
$\mathbf{2}^{\circ}$ & 1 & 1 \\
$\mathbf{3}^{\circ}$ & 1 & 1 \\
$\mathbf{4}^{\circ}$ & 0,9 & 1 \\
$\mathbf{5}^{\circ}$ & 0,8 & 0,7 \\
$\mathbf{6}^{\circ}$ & 0,8 & 0,9 \\
$\mathbf{7}^{\circ}$ & 0,8 & 0,9 \\
$\mathbf{8}^{\circ}$ & 0,8 & 0,9 \\
$\mathbf{9}^{\circ}$ & 0,7 & 0,8 \\
$\mathbf{1 0}^{\circ}$ & 0,7 & 0,8 \\
\hline Total & $\mathbf{0 , 8}$ & $\mathbf{0 , 9}$ \\
\hline
\end{tabular}

Fonte: PNAD/IBGE, 2003.

* Ordenação segundo a renda familiar per capita; renda padronizada feminina dividida pela renda padronizada masculina.

Logo, não é verdade que em qualquer circunstância as mulheres pobres se encontram em situação mais desfavorável do que os homens que compartilham com elas a mesma classe de renda e posição na famí- 
lia. Os diferenciais de rendimento no trabalho variam entre os sexos sensivelmente em razão da posição na família e da classe de renda, revelando que as desigualdades sociais não reproduzem forçosamente as mesmas hierarquias de gênero.

Cabe recordar que, à medida que se sobe na curva da distribuição de renda, o grau de escolaridade não parece ser a variável que possa justificar rendimentos mais elevados para os homens vis-à-vis às mulheres. Se desagregarmos os dados relativos aos anos de estudos concluídos por decil da distribuição, veremos que em todas as classes de renda, sem exceção, as mulheres registram escolaridade média superior à masculina, como atesta a Tabela 19, exceto no decil mais alto.

Tabela 19

Número Médio de Anos de Estudo Concluídos segundo o Sexo e o Decil de Renda Familiar Per Capita da População Ativa - Brasil, 2003

\begin{tabular}{c|c|c}
\hline & Masculino & Feminino \\
\hline $1^{\circ}$ & 4,90 & 5,85 \\
$2^{\circ}$ & 4,99 & 5,60 \\
$3^{\circ}$ & 5,78 & 6,28 \\
$4^{\circ}$ & 6,17 & 6,64 \\
$5^{\circ}$ & 6,71 & 7,19 \\
$6^{\circ}$ & 7,33 & 7,83 \\
$7^{\circ}$ & 7,65 & 7,94 \\
$8^{\circ}$ & 8,63 & 9,07 \\
$9^{\circ}$ & 9,92 & 10,27 \\
$10^{\circ}$ & 12,44 & 12,67 \\
\hline Total & 7,9 & 8,3 \\
\hline
\end{tabular}

Fonte: PNAD/IBGE, 2003.

Intuitivamente, a Tabela 18 sugere ser a definição da chefia familiar nos arranjos nucleares tributária de uma norma de mercado, qual seja a referência é dada pelo maior salário e não mais por critérios não-mercantis (autoridade, senhoridade).

Constata-se, assim, que as mulheres mudaram, e também as famílias, mas o que não parece ter mudado é o compromisso e a responsabilidade que têm as mulheres para com crianças e dependentes idosos - ou seja, para com a esfera familiar-, qualquer que seja o tipo de família em que se encontrem inseridas. A sobrecarga é evidente, pois assumem sozinhas grande parte dos ônus, se pessoas de referência, ou comprome- 
tem as chances de crescimento profissional, se cônjuges. A PNAD de 2003, para a faixa etária de 16 a 65 anos, indica que, enquanto as mulheres dedicam 28 horas por semana em média às tarefas domésticas (36 horas se inativas e 23 horas se ocupadas), os homens ${ }^{7}$, quando o fazem, despendem menos tempo, em média 11 horas (14 horas se inativos e 10 horas se ocupados). Sem contar que também no trabalho doméstico se reproduz a divisão sexual presente no mercado de trabalho: homens e mulheres realizam atividades bastante distintas, sobretudo em termos valorativos e de interesse, como têm demonstrado inúmeras pesquisas sobre orçamento, tempo e articulações entre emprego, família e gênero (Scalon e Araújo, 2004).

Disso já sabem os europeus, que enfatizam a adoção por parte dos países-membros da União Européia de "políticas amigáveis de gênero" (Esping-Andersen, 2002) para aprimorar o sistema de proteção social, de modo a reduzir trade-offs entre vida familiar e carreira e elevar o grau de inclusão social, reduzindo níveis de vulnerabilidade que são incompatíveis com padrões elevados de eqüidade social e bem-estar. Essas políticas amigáveis de gênero, amplamente exitosas no caso da Dinamarca, consistiriam em garantir o suporte institucional para compatibilizar vida produtiva e vida familiar, diminuindo custos e aumentando benefícios. No entender de Esping-Andersen (idem), as políticas amigáveis de gênero são forçosamente amigáveis também para as famílias, com retornos não apenas para as mulheres, mas para a sociedade no seu conjunto.

Resumidamente, podemos concluir que:

1) a ausência ou presença de crianças é determinante na posição ao longo da curva de distribuição de renda, seu número aumentando na cauda inferior da curva e diminuindo nos decis superiores. Logo, toda política que pretenda ter impacto redistributivo deve privilegiar as crianças, pois elas se concentram nos decis inferiores da distribuição, sendo sua presença fator do aumento da vulnerabilidade das famílias;

2) na posição de cônjuge, a inserção feminina, em todas as classes de renda, no mercado de trabalho mostra-se mais desfavorável do que para as chefes, em todas as classes de renda. Pode-se formular a hipótese de que o custo social da conjugalidade (relações de subordinação e dependência), de difícil estimação, seria, portanto, assumido muito mais pelas mulheres do que pelos homens, afetando diretamente sua trajetória ocupacional. Esse custo seria maior, inclusive, do que os cus- 
tos da maternagem e dos cuidados com os filhos e/ou familiares. Entretanto, na posição de referência, as mulheres se encontram sozinhas, assumindo, assim, com ônus elevadíssimo, desafios profissionais e responsabilidades familiares. Em ambas as situações o que pode contribuir para ampliar a autonomia e favorecer sua inserção ocupacional é a redução do tempo e dos custos com encargos domésticos relacionados à educação das crianças e aos cuidados com idosos. Para isso, é necessário assegurar o acesso universal a creches e pré-escolas, promover a escola em tempo integral, sem condicionalidades (ou seja, sem discriminar as inativas), o mesmo devendo ocorrer nos centros de convivência para a terceira idade, além de implementar uma política universal de transferência de renda às famílias com crianças até 16 anos, portanto, aquelas famílias onde predominam os ativos adultos - na sua maioria trabalhadores -, as mais vulneráveis e desprotegidas;

3) as políticas de apoio à família - tanto as de renda, quanto o acesso a serviços e equipamentos - devem ser universais e estar dissociadas da condição ocupacional das mulheres.

4) observa-se forte heterogeneidade entre as mulheres, fato que deve ser considerado na formulação de políticas públicas e sociais voltadas para a redução dos hiatos de gênero;

5) devem ser adotadas iniciativas, no plano fiscal e tributário, que favoreçam os arranjos familiares com filhos - quaisquer que sejam esses arranjos - e que garantam compensações a famílias monoparentais com filhos, oferecendo inclusive compensação pelas despesas relativas à creche, pré-escola e outras formas de guarda. Tal medida seria extremamente favorável às mulheres em geral e, em particular, àquelas chefes de família, reduzindo diferenciais de gênero;

6) os investimentos sociais - escola de qualidade, escola em tempo integral, creches, daycare, transportes públicos de qualidade etc. - contribuem para a elevação da renda das mulheres trabalhadoras porque tendem a ampliar sua capacidade contributiva, liberando seu tempo de trabalho e alargando e fortalecendo sua autonomia no âmbito das relações de gênero, o que tem rebatimentos diretos e positivos na redução da pobreza. 


\section{FATORES QUE CONTRIBUEM PARA A VULNERABILIDADE FAMILIAR}

É senso comum que os arranjos familiares em situação de risco e de maior vulnerabilidade são aqueles chefiados por mulheres sozinhas. Ou seja, a falência do modelo patriarcal de família, que tem na figura masculina o papel do provedor, estaria levando a um empobrecimento crescente das novas gerações, na medida em que muitas crianças estariam sendo criadas, cuidadas e educadas em famílias monoparentais femininas, logo, exclusivamente por mulheres, cuja posição no mercado de trabalho é, comparativamente à dos homens, inquestionavelmente mais desfavorável (salários em média inferiores, menor jornada semanal de trabalho e maior taxa de desemprego etc.).

As tabelas e dados apresentados na primeira parte deste trabalho sugerem, no entanto, que mesmo nas classes de renda mais baixa, e por isso mais vulneráveis - a vulnerabilidade é aqui expressa exclusivamente com base em um determinado nível de renda -, os arranjos familiares com presença de crianças cuja pessoa de referência é do sexo feminino não estariam sempre e forçosamente na condição mais crítica, como induz o framework da feminização da pobreza, que, ao hierarquizar os mais pobres dentre os pobres, identifica as mulheres chefes de família como os indivíduos mais carentes, no fundo do poço, em termos de destituição.

Não se discute a evidência de que a grande maioria das nossas crianças vive em famílias que se encontram nos cinco primeiros décimos da distribuição de renda ${ }^{8}$. É bom recordar que, entre os $10 \%$ mais pobres do país, metade são crianças e a outra metade, adultos em idade de trabalhar. A Tabela 20, que toma como linha de pobreza meio salário mínimo per capita como renda familiar, mostra que o quadro era distinto em 1981, quando os adultos em idade de trabalhar constituíam cerca de $45 \%$ dos pobres, contra 53\% estimados em 2003. Naquela época, a taxa de atividade das mulheres era bem menor, logo a renda familiar era proporcionalmente mais tributária do trabalho masculino. Além disso, a razão de dependência era mais elevada, pois era também mais alta a taxa de fecundidade, sendo maiores as famílias. Houve uma redução significativa no percentual de crianças entre os pobres no período de 1981 a 2003, o mesmo ocorrendo com os idosos ${ }^{9}$. Portanto, nossas crianças são pobres porque seus pais, na maioria trabalhadores, são pobres e não porque a razão de dependência seja alta. 
Tabela 20

Percentual de Pessoas com Renda Familiar Per Capita Menor ou Igual a Meio Salário Mínimo, segundo o Sexo e a Faixa Etária - Brasil, 1981 e 2003*

\begin{tabular}{l|ccc|ccc}
\hline & \multicolumn{3}{|c|}{ 1981 } & \multicolumn{3}{c}{2003} \\
\hline & Masculino Feminino & Total & Masculino Feminino & Total \\
\hline Menos de 16 anos & 54 & 49 & 51 & 48 & 41 & 44 \\
De 16 a menos de 60 anos & 41 & 45 & 43 & 49 & 55 & 52 \\
De 16 anos a menos de 65 anos & 43 & 47 & 45 & 50 & 56 & 53 \\
60 anos e mais & 5 & 6 & 6 & 4 & 4 & 4 \\
65 anos e mais & 4 & 4 & 4 & 2 & 3 & 2 \\
\hline Todas as idades & $\mathbf{1 3 . 2 3 5 . 3 1 9}$ & $\mathbf{1 4 . 1 3 7 . 1 1 7}$ & $\mathbf{2 7 . 3 7 2 . 4 3 6}$ & $\mathbf{2 0 . 2 0 2 . 8 0 7}$ & $\mathbf{2 2 . 3 8 1 . 2 6 9}$ & $\mathbf{4 2 . 5 8 4 . 0 7 6}$ \\
\hline
\end{tabular}

Fonte: PNAD/IBGE, 2003.

* Dados para a população urbana.

A dúvida que persiste é saber qual o fator que mais contribui para uma família ser vulnerável, se ter crianças ou se ser chefiada por mulheres, quase sempre sozinhas, que, por sua inserção menos favorável no mercado de trabalho e oportunidades de emprego mais restritas, acabariam limitadas no desenvolvimento do seu potencial produtivo, com implicações negativas no enfrentamento das suas obrigações familiares. Evidentemente, a conjugação dos dois fatores só viria a agravar o quadro de vulnerabilidades, tal como indica o senso comum.

Para responder a essa pergunta, resolvemos estimar a influência de cada uma das variáveis utilizadas na caracterização dos arranjos familiares (primeira parte deste trabalho) no cálculo da probabilidade de uma família ser vulnerável ou não (Tabela 21). Para isso, empregamos um modelo de regressão logística e definimos vulnerabilidade tomando como parâmetro uma determinada renda familiar per capita e extrapolando o conceito de pobreza relativa. Ou seja, esse modelo foi estimado com base na construção de uma linha de pobreza relativa equivalente a 40\% da renda familiar per capita mediana para o país em 2003. Ampliamos esse valor em 20\%, considerando que há uma intensa mobilidade acima e abaixo da linha de pobreza relativa, em razão da elevada insegurança socioeconômica, que coloca em risco aqueles imediatamente acima da linha de pobreza, qualquer que seja ela. Nossa tentativa, portanto, foi a de incluir esse contingente potencialmente vulnerável àquele identificado como de fato vulnerável. A linha de vulnerabilidade foi, portanto, estimada em $\mathrm{R} \$ 91,20$ (em valores correntes de setembro de 2003). Em outras palavras, as famílias vulneráveis para 
efeitos deste estudo são aquelas com renda inferior a $40 \% *(1,2)=48 \%$ da RFPC mediana.

Tabela 21

Coeficientes Estimados pelo Modelo

\begin{tabular}{l|c}
\hline Variável & $\beta$ \\
\hline Número de adolescentes & 0,3031 \\
Número de idosos com aposentadoria ou pensão & $-1,6473$ \\
Número de idosos sem aposentadoria ou pensão & 0,3161 \\
Número de crianças & 0,9132 \\
Sexo do chefe de família & 0,0232 \\
Chefes ocupados & $-0,8291$ \\
Presença de cônjuge & \\
Cônjuge ocupado & 0,8503 \\
Cônjuge desocupado ou inativo & 0,6135 \\
Constante & $-2,3837$ \\
\hline
\end{tabular}

A Tabela 21 com os resultados dos coeficientes estimados pelo modelo de regressão adotado traz conclusões surpreendentes. Uma primeira constatação - e não das menos relevantes - é a de que o sexo da pessoa de referência na família não é variável de impacto na determinação da vulnerabilidade $(0,232)$. Embora o sexo do chefe não tenha sido rejeitado pelo modelo, sua contribuição à vulnerabilidade de uma família é diminuta. Logo, uma família chefiada por uma mulher (freqüentemente sozinha) ou por um homem (na sua esmagadora maioria com cônjuge) tem chances praticamente idênticas, todo o resto mantido constante, de ser vulnerável. Isso significa dizer que as famílias chefiadas por mulheres, com ou sem cônjuge, não estão mais expostas ao risco da pobreza do que as famílias nucleares tradicionais. O grau de vulnerabilidade de uma família independe de o chefe ser homem ou mulher.

Um segundo resultado de grande interesse é constatar que a redução na probabilidade de uma família ser vulnerável verificada no caso das famílias biparentais é muito inferior ao impacto produzido pela presença de um idoso titular de uma aposentadoria ou pensão. Em outras palavras, ter um idoso na família é estrategicamente mais eficaz na redução da vulnerabilidade do que contar com a presença de um cônjuge (modelo de família nuclear tradicional, onde tal função cabe às mulheres), esteja ele (ou quase sempre ela) trabalhando (cônjuge 2-2) ou não (cônjuge 2-1). Como revelam os dados, um chefe de família ocupado, 
seja ele homem ou mulher, tem forte impacto na redução da probabilidade de uma família ser vulnerável, mas esse impacto é metade daquele estimado quando da presença na família de idosos detentores de uma aposentadoria ou pensão. Já a presença de um cônjuge - independente do sexo-, ao invés de reduzir o risco de vulnerabilidade, tem impacto significativo e elevado na chance de uma família ser vulnerável. Estando o cônjuge ocupado, o coeficiente é cerca de $30 \%$ menor do que o estimado no caso de cônjuge desocupado, mas, ainda assim, contribui para aumentar a probabilidade de uma família ser vulnerável (duas vezes mais, por exemplo, do que a presença de adolescentes).

É incontestável que a presença de idosos aposentados ou pensionistas reduz significativamente a probabilidade de uma família ser vulnerável. Isso se explica pelo fato de, mesmo entre as camadas mais pobres da população, haver hoje o acesso a uma renda mínima garantida, mediante o Benefício de Prestação Continuada - BPC da Lei Orgânica da Assistência Social - LOAS, no valor de um salário mínimo, com cobertura ampla e eficaz. Portanto, a terceira constatação que se impõe é que a presença de um idoso aposentado ou pensionista é o fator que mais contribui para diminuir o risco de vulnerabilidade nas famílias pobres e carentes. Em outras palavras, dispormos no Brasil de uma política social que garante renda aos idosos, no patamar expressivo de um salário mínimo, é o que hoje mais contribui para reduzir a vulnerabilidade dos pobres no país, como revelam as estimativas do modelo aqui aplicado.

Outra evidência vem corroborar o que é amplamente conhecido: onde há crianças, é elevadíssima a probabilidade de uma família ser vulnerável, a mais forte estimada pelo modelo. Observe-se que a variável presença de crianças (até 16 anos) registra um coeficiente três vezes maior do que aquele observado no caso da presença de adolescentes (17 a 24 anos) ou mesmo de idosos que não usufruem de qualquer benefício previdenciário. Isso significa dizer que uma criança provoca impacto negativo três vezes maior na probabilidade de uma família ser vulnerável do que a presença de outros tipos de dependentes, sejam eles adolescentes ou idosos sem cobertura previdenciária.

Finalmente, cabe destacar um resultado, que contradiz o senso comum, apontado ao longo deste artigo. Da mesma maneira que o sexo do chefe é quase indiferente na probabilidade de uma família ser mais ou menos vulnerável, o perfil da família, se biparental (chefe, geralmente homem, e cônjuge) ou monoparental (entenda-se chefia femini- 
na), tampouco tem peso expressivo na explicação da vulnerabilidade. Esse resultado contradiz a compreensão vulgar de que as famílias monoparentais com filhos encontram-se bem mais expostas ao risco de vulnerabilidade do que as famílias nucleares também com filhos, que respondem ao modelo ainda prevalecente entre nós. A presença de um casal à frente de uma família reduz muito pouco a probabilidade desta ser vulnerável vis-à-vis a contribuição dada pela chefia única (família monoparental).

Além dos coeficientes retratados na Tabela 21, agregamos à nossa análise (Tabela 22) um exercício extra, calcado na construção de uma família hipotética, reproduzindo, no entanto, a presença de filhos e o perfil biparental ou monoparental. Os percentuais relativos à probabilidade estimada pelo modelo ${ }^{10}$, conforme os dois tipos de famílias e a presença ou não de crianças, adolescentes e idosos, estão assinalados na Tabela 22.

Tabela 22

Probabilidade de Vulnerabilidade das Famílias - Estimativas do Modelo

\begin{tabular}{l|c|c|c|c}
\hline & Fam1 & Fam2 & Fam3 & Fam4 \\
\hline Chefe homem, casal com filhos, cônjuge desocupado & $31,74 \%$ & $8,32 \%$ & $6,92 \%$ & $1,41 \%$ \\
Chefe mulher sem cônjuge, com filhos & $37,45 \%$ & $1,06 \%$ & $8,79 \%$ & $1,82 \%$ \\
\hline
\end{tabular}

Resumidamente, observamos que:

1) a probabilidade de uma família sem crianças ser vulnerável varia entre 1,4\% e 8,8\%, em virtude da presença ou não de um idoso detentor de um benefício previdenciário e da existência de um cônjuge ocupado;

2) essa mesma configuração familiar, isto é, sem a presença de crianças, revela que as famílias monoparentais femininas registram probabilidade de serem vulneráveis muito semelhante àquela observada nas famílias biparentais chefiadas por homens. Essa diferença é menor do que $0,5 \%$ quando se verifica presença de aposentados/pensionistas e alcança aproximadamente $2 \%$ quando não há aposentados;

3) considerando-se a presença de crianças na família ${ }^{11}$, o que eleva em muito a probabilidade de qualquer tipo de arranjo familiar ser vulnerável, as famílias monoparentais têm mais chance de serem vulneráveis do que aquelas biparentais nas quais o cônjuge se encontra desocupado. O mais interessante, porém - e que merece destaque-, é a pequena margem de desvantagem, muito aquém do que se poderia imaginar, da ordem apenas de 15\%, quando não se registra presença de aposenta- 
dos / pensionistas na família, caindo para 2,2\% quando esses estão presentes. Portanto, o que é digno de nota é a constatação de que a probabilidade de uma família monoparental feminina ser vulnerável é, na pior as hipóteses, pouco maior do que a de uma família biparental de chefia masculina.

Nessa mesma linha de raciocínio, constatamos ainda que a presença de um cônjuge ocupado (o que ocorre apenas nas famílias biparentais) reduz significativamente a probabilidade de uma família ser vulnerável. Os dados empíricos mostraram, na parte inicial do artigo, que a maioria das cônjuges está fora do mercado de trabalho. Isso significa que se fosse possível às famílias biparentais liberar e valorizar o potencial de trabalho feminino, e, dessa maneira, ampliar as oportunidades de emprego dos cônjuges, na sua maioria mulheres, as chances de tais famílias saírem da pobreza aumentariam. Ora, o que restringe tal potencial - para além dos constrangimentos derivados da dinâmica inerente ao mercado de trabalho ao reproduzir as desigualdades de gênero (baixa mixidade ocupacional, diferenciais salariais) - é o efeito conjugalidade. Em todas as composições familiares analisadas, observamos que os cônjuges mulheres, em famílias com ou sem crianças, mostraram desempenho inferior ao das mulheres chefes ${ }^{12}$ (taxa de atividade, rendimentos do trabalho, horas trabalhadas etc.). Portanto, o que represa uma melhor inserção feminina no mercado de trabalho - todo o resto mantido constante - é menos o fator presença de crianças (leia-se cuidados de maternagem) e mais o contrato conjugal, que coloca as mulheres em uma relação de subordinação e dependência no âmbito familiar e da divisão sexual do trabalho, reduzindo sua autonomia. Tolhidas não apenas por afazeres domésticos (fato que afeta a todas as mulheres), mas também limitadas no seu desenvolvimento por uma relação contraditória e assimétrica estruturada em um modelo patriarcal no qual a figura masculina é a do provedor tradicional, as mulheres na posição de cônjuges acabam reduzindo seu escopo de oportunidades de emprego, notadamente nas camadas mais pobres, no afã de conciliar encargos familiares e trabalho.

Podemos, portanto, concluir que sempre que for possível reduzir os trade-offs entre trabalho e família, externalizando os conflitos de gênero derivados da disputa em torno à alocação do tempo de trabalho doméstico, reduzindo-o para todos os membros - embora se trate de um tempo ainda e consistentemente assumido pelas mulheres -, mediante a provisão de serviços públicos, estar-se-á contribuindo para alavan- 
car o potencial produtivo das mulheres em geral, e notadamente daquelas que se encontram na posição de cônjuges, ou seja, em uma posição subordinada. Para isso, mais do que transferências de renda monetária às famílias carentes, é indispensável retomar o investimento público na escola de tempo integral, com ensino de qualidade, e ampliar a oferta de creches, por parte das prefeituras, para crianças na faixa pré-escolar, de modo a galvanizar a autonomia das mulheres. Só a universalização do acesso e do padrão de qualidade dos serviços desmercantilizados são capazes de reduzir profunda e rapidamente os diferenciais de gênero e as desigualdades sociais no país. Políticas de renda bem desenhadas, como é o caso da garantia de renda mínima para idosos carentes com mais de 65 anos (BPC), são indispensáveis na redução da probabilidade de uma família ser vulnerável, mas insuficientes para reverter a pouca contribuição do trabalho remunerado das mulheres cônjuges à diminuição da pobreza e da iniqüidade. O que falta ao Brasil é desenhar uma política universal de renda voltada para famílias com crianças, para atuar com efetividade na redução das vulnerabilidades e das desigualdades sociais. Estas atingem a todas as famílias em situação de insegurança socioeconômica, independente do sexo do chefe e do seu perfil (mono ou biparental).

(Recebido para publicação em novembro de 2005)

(Versão definitiva em janeiro de 2006) 


\section{NOTAS}

1. Em Lavinas (2001:12, Gráfico 8), observa-se, com base em médias móveis, uma evolução positiva do índice de rendimentos do trabalho das mulheres vis-à-vis os homens no período 1982-1998. A redução do hiato salarial foi ainda mais acentuada na década de 1990, quando a recuperação dos salários femininos se deu em progressão bem superior à dos homens.

2. Cabe assinalar que, desde 2001, o Código Civil brasileiro eliminou a referência à chefia masculina na sociedade conjugal; para fins deste artigo, porém, estaremos usando alternadamente as palavras chefia, chefe ou pessoa de referência.

3. Isso explica por que o número de famílias varia tanto entre os décimos da distribuição.

4. Essencialmente, licença-maternidade e estabilidade para as gestantes.

5. Os dados relativos às famílias monoparentais com pessoa de referência do sexo masculino, por serem de peso absolutamente inexpressivo, são computados no item $\mathrm{Ou}$ tros. Logo, na prática, essa categoria, no caso brasileiro, não tem equivalente para os homens.

6. Foram computados aqui os empregados e as domésticas.

7. Conforme assinalam Goldani e Verdugo Lazo (2004), com base na Pesquisa sobre Padrões de Vida do IBGE, de 1998, menos de 30\% dos homens declaram estar envolvidos com algum tipo de função do lar, contra $79 \%$ das mulheres.

8. Ver, a esse respeito, Lavinas e Garson (2004).

9. A análise detalhada dessa tendência e de suas causas foi amplamente discutida por Lavinas e Dain (2005) e Lavinas (2005); por essa razão, não desenvolveremos tal análise no âmbito deste artigo.

10. Ver metodologia detalhada desse exercício no Anexo Estatístico.

11. O exercício adotado considerou famílias com presença de duas crianças, tipo padrão.

12. Não vamos esquecer que as mulheres chefes são majoritariamente mães com crianças. 


\section{REFERÊNCIAS BIBLIOGRÁFICAS}

BELTRÃO, K. I. e ALVES, J. E. D. (2004), “A Reversão do Hiato de Gênero na Educação Brasileira no Século XX". Anais do XIV Encontro Nacional de Estudos Populacionais, Campinas, SP, ABEP, vol. 1.

ESPING-ANDERSEN, C. (2002), Why We Need a New Welfare State? Oxford, Oxford University Press.

GOLDANI, A. M. e VERDUGO LAZO, A. (2004), Brasil: Desafios de Políticas para Famílias. Trabalho apresentado no seminário Cambio de las Familias en el Marco de las Transformaciones Globales: Necesidad de Políticas Públicas Eficaces, Santiago, Cepal, 28-29 de outubro.

GUEDES, M. C. (2004), As Mulheres de Formação Universitária: A Reversão da Desigualdade de Gênero e seus Reflexos no Mercado de Trabalho. Brasil: 1970-2000. Dissertação de Mestrado, Programa de Estudos Populacionais e Pesquisas Sociais, ENCE.

IBGE. (1982), Pesquisa Nacional por Amostra de Domicílios 1981.

. (2004a), Pesquisa Nacional por Amostra de Domicílios 2003.

. (2004b), Sintese de Indicadores Sociais.

LAVINAS, L. (2001), “Empregabilidade no Brasil: Inflexões de Gênero e Diferenciais Femininos". Textos para Discussão, no 826, Ipea, p. 44.

. (2004), "Universalizando Direitos", in Social Watch Brasil. Observatório da Cidadania - Relatório 2004, Medos e Privações, pp. 67-74.

. (2005), “Salário Mínimo, Linha de Pobreza e Benefícios Assistenciais: Desvincular é Preciso?", in P. Baltar et alii, Salário Mínimo e Desenvolvimento. Unicamp, Instituto de Economia, pp. 121-136.

e DAIN, S. (2005), Proteção Social e Justiça Redistributiva: Como Promover a Igualdade de Gênero. Convênio Fase-Novib, Relatório Final. Manuscrito, 75 p. Disponível em: www.ie.ufrj.br/aparte.

LAVINAS, L. e GARSON, S. (2004), “O Gasto Social no Brasil: Transparências, sim, Partis-pris, não". Econômica, vol. 5, no 1, pp. 145-162.

SCALON, C. e ARAÚJO, C. (2004), Gênero, Família e Trabalho. Pesquisa realizada no âmbito do International Social Survery Programme, Rio de Janeiro, IUPERJ/UERJ.

SILVA, E. e SCHWARZER, H. (2002), “Proteção Social, Aposentadorias, Pensões e Gênero no Brasil". Textos para Discussão, no 934, Ipea, Brasília, p. 55.

SORJ, B. (2004), "Reconciling Work and Family: Issues and Policies in Brazil". Conditions of Work and Employment Series, no 8, International Labour Office, Genève, pp. 1-69. 


\section{ANEXO ESTATÍSTICO}

Neste artigo utilizamos o modelo de regressão logística, útil para estimar a probabilidade de ocorrência de um evento quando a variável dependente é binária. Este tipo de modelagem torna-se interessante neste contexto específico, se comparado ao modelo de regressão linear, sobretudo pelo caráter discricionário e qualitativo da resposta do fenômeno, traduzido pela característica, bem definida, de condição dicotômica da vulnerabilidade ou não das famílias.

A variável resposta do modelo é a vulnerabilidade da família, assumindo valor 1, quando a família é vulnerável, e valor 0 , caso contrário. A vulnerabilidade da família foi considerada tomando por base a linha de pobreza relativa de $40 \%$ da renda familiar per capita (RFPC) mediana da população brasileira, em setembro de 2003. Considerando que as famílias vulneráveis encontram-se em uma zona mais ampla, acima e abaixo da linha de pobreza, agregamos ao valor da renda familiar per capita mediana $20 \%$, incluindo, portanto, na condição de vulneráveis todas as famílias com a RFPC inferior à R\$91,20. Em resumo, a linha da vulnerabilidade, então, contempla as famílias com RFPC menor ou igual a $48 \%$ da renda familiar per capita mediana do Brasil. Como variáveis explicativas foram testadas duas variáveis binárias, quatro numéricas, e uma variável categórica, sendo elas, respectivamente: o sexo do chefe da família, assumindo valor 0 para masculino e valor 1 para feminino; a ocupação do chefe da família, com valor 1 para ocupados e 0 para desocupados ou inativos; número de idosos sem aposentadoria ou pensão na família; número de idosos com aposentadoria ou pensão na família, número de crianças na família; número de adolescentes na família; além da situação do cônjuge na família, com valor 0 para famílias sem cônjuge, valor 1 para famílias com cônjuges desocupados ou inativos e valor 2 para famílias com cônjuges ocupados.

Assume-se que cada resposta individual da variável vulnerabilidade da família é independente, seguindo uma distribuição de Bernoulli, e a proporção entre o número acumulado de sucessos na variável resposta e o total de observações, nos determinados grupos das variáveis binárias explicativas, segue uma distribuição binomial. Definida a distribuição de probabilidade da variável resposta, basta escolher a função de ligação, que relaciona a esperança da variável resposta com o previsor linear. Neste exercício será utilizada como função de ligação a lo- 
git(p), que associa o logaritmo da vantagem em favor do evento considerado com o previsor linear. Assim:

Dois testes foram produzidos através do pacote estatístico SPSS para a avaliação do modelo e seus parâmetros:

- Teste de hipóteses sobre os coeficientes: para grandes amostras, a estatística de Wald pode ser utilizada para testar se os coeficientes são iguais a zero. Essa estatística tem distribuição qui-quadrado com grau de liberdade $(\mathrm{n}-\mathrm{p})$, onde $n$ é o número de observações e $p$ o número de parâmetros estimados. A hipótese nula é de que o coeficiente do parâmetro é igual a 0 .

- Teste de hipóteses sobre a inclusão de variável: a fim de comparar os modelos contemplando cada uma das variáveis explicativas, foi utilizada a estatística da razão de verossimilhança, que é o quociente entre a verossimilhança do modelo avaliado e a do reduzido.

O teste da razão de verossimilhança analisa as mudanças no log da verossimilhança quando cada variável é acrescentada ao modelo estimado. O teste é feito dividindo a verossimilhança do modelo reduzido, contendo apenas o intercepto, e o modelo maximal, que seria aquele a ser testado. Para grandes amostras, a deviance - duas vezes o log da razão de verossimilhança - tem distribuição qui-quadrado com grau de liberdade $(n-p)$, onde $n$ é o número de observações e $p$ o número de parâmetros estimados. A hipótese nula é de o modelo reduzido ser tão bom quanto o modelo testado.

Tabela A

Estimação dos Parâmetros do Modelo

\begin{tabular}{|c|c|c|c|c|c|c|c|}
\hline Variável & $\beta$ & S.E. & Wald & $\mathrm{df}$ & Sig & $\mathbf{R}$ & $\operatorname{xp}(\varphi)$ \\
\hline co de a & 3031 & 005 & 3597 & 1 & 000 & 0,0825 & 1,354 \\
\hline senta & $-1,6473$ & 0,0017 & 993 & 1 & 0,000 & $-0,1371$ & 0,1926 \\
\hline $\begin{array}{l}\text { Número de idose } \\
\text { sentadoria ou }\end{array}$ & 0,3161 & 0,0016 & 3810 & 1 & 0,000 & 0,0268 & 1,3717 \\
\hline & & & 5908 & 1 & & & \\
\hline Sexo & 0,0232 & 0,0014 & 270,7791 & 1 & 0,000 & 0,0023 & 1,0234 \\
\hline Chefes oc & $-0,8291$ & 0,0012 & 515162,6 & 1 & 0,000 & $-0,0987$ & 0,4364 \\
\hline & & & 577239,7 & 2 & 0,000 & & \\
\hline Cônjuge ocupado & 0,8503 & 0,0014 & 345264,8 & 1 & 0,000 & 0,0808 & 2,3404 \\
\hline $\begin{array}{l}\text { Cônjuge desocupado ou } \\
\text { inativo } \\
\text { Constante }\end{array}$ & $\begin{array}{r}0,6135 \\
-2,3837 \\
\end{array}$ & $\begin{array}{c}0,001 \\
0,0014\end{array}$ & $\begin{array}{r}387825,9 \\
2726549\end{array}$ & $\begin{array}{l}1 \\
1\end{array}$ & $\begin{array}{l}0,000 \\
0,000 \\
\end{array}$ & 0,0857 & 1,8469 \\
\hline
\end{tabular}


Utilizando o modelo descrito acima, foi realizado também o exercício de cálculo das probabilidades, para quatro formações específicas de famílias, conforme valores arbitrados para cada uma das variáveis explicativas, a fim de comparar famílias chefiadas por homens com cônjuge ocupado/a e aquelas chefiadas por mulheres sem cônjuge. As famílias consideradas, além de variarem segundo o sexo do chefe e a presença de cônjuge ocupado/a, tiveram as seguintes conformações: família 1 (Fam1), nenhum idoso, nenhum adolescente, duas crianças e chefe ocupado; família 2 (Fam2), um idoso com aposentadoria ou pensão, nenhum adolescente, duas crianças e chefe ocupado/a; família 3 (Fam3), nenhum idoso, nenhum adolescente, nenhuma criança, com filhos (adultos) e chefe ocupado/a; família 4 (Fam4), um idoso com aposentadoria ou pensão, nenhum adolescente, nenhuma criança, com filhos (adultos) e chefe ocupado/a. 


\section{ABSTRACT \\ Work and Vulnerability: What Are the Family Arrangements at Risk?}

The purpose of this article is to compare different family models according to the typology proposed by the IBGE (Brazilian Institute of Geography and Statistics, or National Census Bureau), to verify whether families headed by women really represent the most vulnerable or "at-risk" family arrangement. The latter is the commonsense notion that legitimizes the framework of feminization of poverty, in vogue in the last two decades and with considerable impact on the design of anti-poverty social policies. The current empirical study disaggregates the employment data (employment rate, mean wages, workweek) not only by gender (identifying differences between men and women), but also breaking down the data for women, comparing the situation of women heads-of-families versus wives. In terms of women's full participation in the work market, the effect of conjugality is even more harmful than motherhood (presence of children).

Key words: gender and work market; feminization of poverty; gender inequalities

\section{RÉSUMÉ \\ Activité et Vulnérabilité: Quels Modèles Familiaux Courent des Risques?}

Dans cet article, on cherche à comparer des modèles différents de familles, selon la typologie proposée par l'IBGE, afin de vérifier si les familles dont le chef est une femme constituent en effet l'organisation familiale la plus vulnérable et en péril. C'est une idée courante qui justifie le tableau de féminisation de la pauvreté, si connu dans les vingt dernières années avec des impacts considérables sur les politiques sociales de lutte contre la pauvreté. Dans cette étude, on dégage des données sur les activités - taux d'occupation, salaire moyen, nombre d'heures de travail - non seulement par sexe, identifiant les différences homme-femme, mais on discrimine aussi les femmes entre elles, faisant un parallèle entre celles qui sont chef de famille et celles qui vivent avec leur conjoint. On observe que la vie en couple est plus nuisible à la pleine insertion de la femme sur le marché de travail que les effets même de la maternité (présence des enfants).

Mots-clé: genre et marché de travail; féminisation de la pauvreté; inégalités de genre 